\title{
Penerapan Sistem Sirkulasi Perpustakaan Berbasis SLIMS Pada SMA IT Al Fityah Pekanbaru
}

\author{
Loneli Costaner*1, Guntoro' ${ }^{2}$, Yuhelmi ${ }^{3}$ \\ 1,2,3Program Studi Teknik Informatika, Fakultas Ilmu Komputer, Universitas Lancang Kuning \\ *e-mail: lonelicostaner@gmail.com¹, guntoro@unilak.a.id ${ }_{2}^{2}$ yuhelmi@unilak.ac.id ${ }^{3}$
}

\begin{abstract}
In the world of education there is now an electronic-based learning system that can be used for distance learning. The change in learning from manual to electronic indicates a global change to make it easier for humans to interact without having to meet in person. In the field of computers today we also find many companies, the market and the world of education, including schools, have used information systems based on automation. With the aim of facilitating the processing of data and information can be obtained quickly and accurately. One way to provide good, fast and safe service is a trusted and proven system that is able to provide librarian officers with an open source SLIMS application. SLIMS is an application library that is almost perfect for organizing data data and information needed.
\end{abstract}

Keywords: Library, SLIMS, Education, School, Open Source

\section{Abstrak}

Dalam dunia pendidikan sekarang ada sistem pembelajaran berbasis elektronik yang dapat digunakan untuk pembelajaran jarak jauh. Perubahan belajar dari basis manual ke elektronik justru internet menunjukkan perubahan global untuk memudahkan manusia berinteraksi tanpa harus bertemu. Di bidang komputer saat ini kami juga menemukan banyak perusahaan, pasar dan dunia pendidikan, termasuk sekolah, telah menggunakan sistem informasi berdasarkan otomasi. Dengan tujuan memfasilitasi pengolahan data dan informasi dapat diperoleh dengan cepat dan akurat. Salah satu cara untuk menyediakan layanan yang baik, cepat dan aman adalah sistem yang tepercaya dan terbukti yang mampu memberikan petugas perpustakaan aplikasi SLIMS sumber terbuka. SLIMS adalah perpustakaan aplikasi yang hampir sempurna untuk mengatur data data dan informasi yang dibutuhkan.

Kata kunci: Perpustakaan, Slims, Pendidikan, Sekolah, Open Source

\section{PENDAHULUAN}

Pendahuluan berisi Sekolah Menengah Atas Islami Terpadu AL Fityah Terletak dijalan Swakarya Kel. Tuah Karya, Kec. Tampan - Pku, Kota Pekanbaru, ia berdiri atas komitment dari yayasan YPPSDI Al Fityah untuk mengembangkan pendidikan ke tinggat menegah, sehingga pada tahun 2012 terwujud lah SMA IT Al Fityah dengan SK Dinas pendidikan kota pekanbaru No. 420/SM2/VI/2011/10632 (Syamsul Mubaroq, 2013).

Seiring perjalanan untuk membangun pendidikan yang berkarakter, SMA IT AL FITYAH terus melakukan inovasi terhadap perkembangan dunia pendidikan guna melihat kebutuhan masyarakat dalam dunia kerja maupun yang akan melanjutkan ke pendidikan yang lebih tinggi.

Salah satu yang menjadi perhatian dalam meningkatkan sumber daya manusia yang memiliki skill dan keterampilan siap pakai adalah dengan adanya perpustakaan sekolah yang memuat buku buku dan modul dengan akses yang mudah dan cepat. Dengan adanya pustaka dalam suatu sekolah akan menambah semangat siswa siswi untuk mendapatkan informasi dan ilmu dengan gemar membaca guna meraih prestasi disekolah tempat mereka menimba ilmu (Rahadian \& Anwar, 2014).

Menurut Darwono dalam (Khotimah, 2017) dan (Hikmawan, Astuti, \& Riyadi, 2015), perpustakaan adalah sebuah institusi yang mengumpulkan pengetahuan tersetak serta terekam, dimana data tersebut dikelola secara khusus berguna untuk memenuhi kebutuhan para intlektualitas para yang membutuhkannya melalui berbagai cara intraksi pengetahuan. Sifat dan 
kegunaan perpustakaan yang memiliki fungsi untuk meningkatkan kwalitas pendidikan dengan manfaat untuk mendukung tercapainya tujuan proses belajar mengajar disekolah .

Karena peran perpustakan sangat penting untuk meningkatkan kwalitas pendidikan. Oleh karena itu pengelolaan perpustakaan tidak bisa dilakukan sembarang orang. Peran tenaga perpustakaan dalam mengembangkan perpustakaan sekolah sangat besar. Keterampilan dalam mengelola perpustakaan dan memiliki wawasan untuk menjadi tenaga perpustakaan sekolah (Dewi \& Suhardini, 2014).

Ada beberapa istilah yang berkaitan dengan perpustakaan: (1) Perpustakaan kuno: perpustakaan zaman yang belum memakai catalog, (2) Perpustakaan Tradisional, kumpulan koleksi buku dan tidak ada otomasi katalog, (3) Perpustakaan semi modern, adanya katalogisasi, pengindeksan dan kalsifikasi secara manual dan automasi, (4) Perpustakaan Modern, semuanya automatisasi atau menggunakan komputer sebagai alat bantu layanan perpustakaan dan pengelolaannya, (5) Perpustakaan digital, secara fisik mirip dengan perpustakaan modern, penekanannya lebih pada koleksi, (6) Perpustakaan maya, seluruh koleksinya (Susanto, 2010).

Siswa maupun siswi yang akan meminjam buku baik yang dibaca di ruang baca maupun untuk dibaca dirumah harus mengisi buku pengunjung, data isian, nama pengunjung, tanggal pengunjung. Apabila pengunjung meminjam buku, maka petugas akan memberikan kartu peminjaman buku sebagai pendataan transaksi peminjaman dan waktu pengembalian. Dalam aktifitas pelayanan kepada siswa petugas perpustakaan harus mencari nama pengunjung yang melakukan transaksi di buku manual transaksi hal ini membuat lama proses transaksi peminjaman dan pengembalian buku di perpustakaan. Sehingga diperlukan sebuah alternatif lain untuk mengubah sistem manual kepada sistem otomatis salah satunya menggunakan aplikasi open source SLIMS yang dapat memudahkan pekerjaan pustakawan. Aplikasi perpustakaan SLIMS dikembangkan anak bangsa indonesia yang saat ini sudah digunakan oleh banyak lembaga dan organisasi baik nasional bahkan internalsional, sehingga sangat direkomendasikan untuk kebutuhan sekolah dalam mengelola pustaka yang dimiliki oleh SMA IT AL Fityah Pekanbaru (Azwar, 2013).

Senayan library management system (SLIMS) telah berhasil menjadi software yang paling banyak digunakan oleh perpustakaan di Indonesia, bahkan sudah digunakan oleh perpustakaan di luar negri. Menurut informasi dari wensite resminya, http:slims.web.id/goslims/, sampai saat ini untuk aplikasi terbaru, portable SLIMS 864 bit (x64) saja sudah didownload sebanyak 695.838 kali (Saputra, 2017).

SLIMS adalah sebuah perangkat lunak manajemen perpustakaan yang bersifat gratis dan kode sumber terbuka (free and open source software atau FOSS). Lisensi SLiMS adalah General Public Lisence (GPL) versi 3 yang menjamin kebebasan untuk mendapatkan, menggunakan, mempelajari, mengubah dan mendistribusikan ke pihak lain dengan syarat tidak menghilangkan keterangan kepengarangan dan merubah dengan lisensi lainya (Cahyono \& Heryanto, 2013).

Perangkat lunak ini tidak hanya dapat digunakan untuk mengembangkan otomasi perpustakaan, namun juga dapat digunakan untuk mengelola koleksi digital (membangun perpustakaan digital) dan mengelola koleksi audio serta audio visual yang dapat dinikmati langsung melalui fasilitas web streaming yang disediakan oleh Senayan. Aplikasi SLiMS ini merupakan salah satu sistem automasi perpustakaan yang dapat melakukan kegiatan pengolahan perpustakaan seperti penelusuran Online Public Accses Catalog atau OPAC, layanan sirkulasi, bibliografi, manajemen keanggotaan, pelaporan dan kendali terbitan berseri secara automasi (Rahmadhani \& Marlini, 2015). 


\section{METODE}

Bagian Sasaran kegiatan ini adalah para guru dan petugas Perpustakaan di SMA IT AL Fityah Pekanbaru. Pemilihan dan penetapan sasaran pelatihan ini adalah mempertimbangkan terhadap permasalahan yang dihadapi oleh guru dan petugas tentang penerapan sistem sirkulasi perpustakaan berbasis SLIMS. Pelatihan ini diikuti oleh tenaga perpustakaan sebanyak 2 orang, dimulai dari jam pagi hingga siang hari. Langkah kegiatan yang dilakukan pada pelatihan penerapan aplikasi SLIMS ini adalah (1) Pretest, (2) Ceramah, (3) Demonstrasi, (4) Praktek, (5) Posttest, penjelasan langkah langkah pengabdian dapat dilhat penjelasan berikut ini.

1. Sebelum pelatihan aplikasi slims, tim peneliti mengajukan lembar pretest (test pemahaman secara tertulis tentang aplikasi slims) yang akan di isi oleh peserta pelatihan agar mengetahui sejauh mana peserta mengenal tetang aplikasi.

2. Tim pelaksana mengawali pembukaan, dengan menyampaikan tetang konsep manajemen buku dan perlunya aplikasi perpustakan untuk membantu mempercepat proses pelayanan perpustakaan dan pendataan buku.

3. Media pelatihan menggunakan laptop, komputer, modul slims, buku buku dan infocus agar pelatihan bisa optimal.

4. Pemaparan materi slims, pertama dengan membuat account pustakawan, agar setiap petugas pustaka memiliki hak akses yang berbeda guna keamanan data, materi kedua mengenai pendataan anggota dan klasifikasi anggota, hal ini dilakukan untuk mempermudah pencarian dan hak hak apa saja yang diperlukan oleh anggota, materi ketiga mengenai pendataan buku dan catalog buku, agar memudahkan pencarian buku, penomoran exsemplar buku, materi keempat bagaimana melakukan sirkulasi buku / peminjaman buku, agar peserta mengetahui bagaimana transaksi peminjaman dilakukan dengan mudah menggunakan aplikasi slims, materi ke lima bagaimana melakukan transaksi anggota yang akan memulangkan buku, agar status buku terpinjam kemudian berubah menjadi sudah dikembalikan dan yang trakhir materi membuat laporan, baik laporan peminjaman, laporan denda, laporan data buku dan laporan data anggota

5. Setelah proses pelatihan materi selesai, dilanjutkan dengan sesi diskusi atau Tanya jawab berkenaan pelatihan aplikasi slims

6. Sebelum berakhir pelatihan tim pelaksana meminta peserta megisi form posttest sebagai pengujian dan perbandingan antara sebelum diberikan pelatihan dan sesudah dilaksanakannya pelatihan, guna mengetahui kondisi pemahaman peserta apakah ada materi yang belum bisa dipahami dan diperaktekkan.

\section{HASIL DAN PEMBAHASAN}

Hasil kegiatan pengabdian yang dilakukan di Sekolah Menengah Atas IT AL Fityah pekanbaru dengan tema penerapan sirkulasi perpustakaan berbasis senayan library manajemen sistem berjalan dengan lancar. 


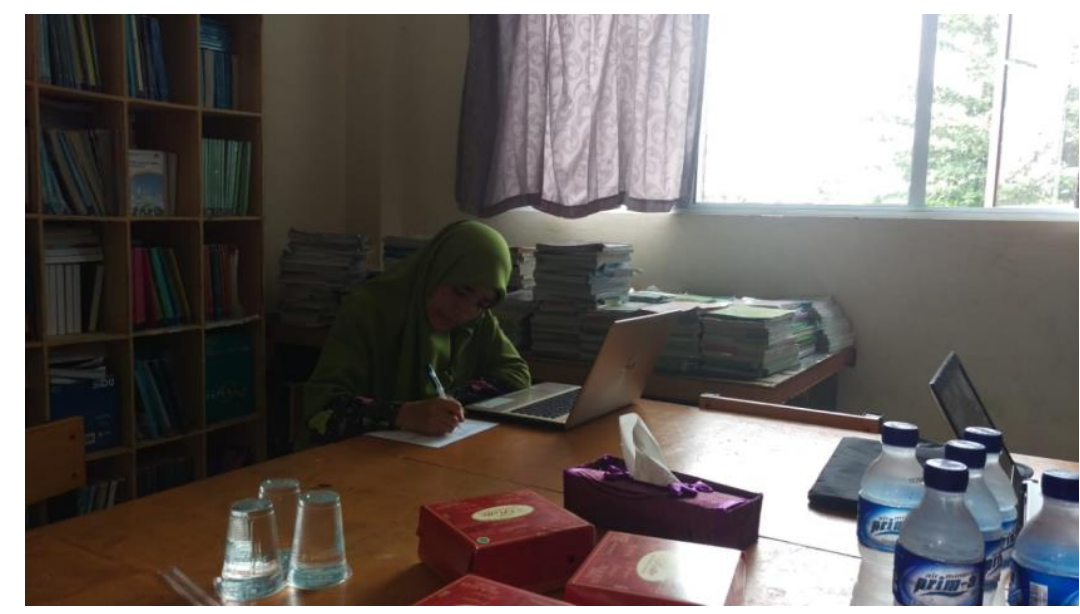

Gambar 1. Peserta pelatihan mengisi lembar pretest

Pelatihan aplikasi slim dilaksanakan dengan baik, dimana peserta pelatihan sangat berpartisipasi mengikuti langkah demi langkah pelatihan aplikasi, mulai dalam mengatur account pustakawan, mengisi data anggota, mengisi data buku, sirkulasi peminjaman dan pengembalian serta laporan perpustakaan.

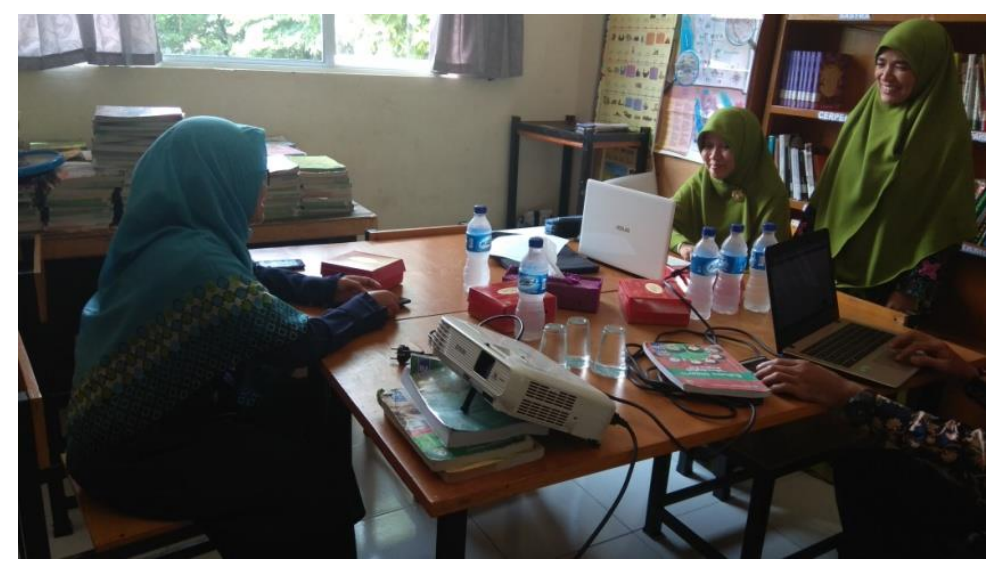

Gambar 2. Praktek pelatihan aplikasi slims

Untuk mengetahui sejauh mana peserta pelatihan perlu adanya uji pemahaman kepada peserta pelatihan, maka dari itu tim pelaksana melakukan test tertulis dari dengan sebuah quisioner / pertanyaan sebanyak 12 point, baik sebelum melaksanakan pelatihan maupun sesudah pelatihan. Untuk menguji data pretest dan posttest menggunakan skala guttman, yaitu sekala yang menginginkan tipe jawaban tegas. Skala guttman yang dirancang oleh tim pelaksana dibuat dengan 2 pilihan tegas, pertama dengan pilihan "YA" akan diberi nilai "1" dan kedua dengan pilihan "TIDAK" akan diberi nilai "0"

\section{Data pretest}

Responden yang mengikuti hingga selesai ada 2 orang, kemudian memberikan gambaran penilaian pretest yang sama, dengan skala guttman pada tabel 1 berikut ini.

Tabel 1 Rekap kuisioner pre-test

\begin{tabular}{|c|c|c|c|c|c|c|c|c|c|c|c|c|c|}
\hline \multirow{2}{*}{ No } & \multirow{2}{*}{$\begin{array}{l}\text { Peserta } \\
\text { Pelatihan } \\
\text { (P) }\end{array}$} & \multicolumn{12}{|c|}{ KUISIONER (K) } \\
\hline & & $\mathrm{K} 1$ & K2 & K3 & $\mathrm{K} 4$ & K5 & K6 & $\mathrm{K} 7$ & K8 & K9 & $\mathrm{K} 10$ & $\mathrm{~K} 11$ & $\mathrm{~K} 12$ \\
\hline 1 & P1 & 1 & 0 & 0 & 0 & 0 & 0 & 0 & 0 & 0 & 0 & 0 & 0 \\
\hline
\end{tabular}




\begin{tabular}{lllllllllllll}
$2 \quad \mathrm{P} 2$ & 1 & 0 & 0 & 0 & 0 & 0 & 0 & 0 & 0 & 0 & 0 & 0 \\
\hline Total & 2 & 0 & 0 & 0 & 0 & 0 & 0 & 0 & 0 & 0 & 0 & 0 \\
\hline
\end{tabular}

Total Data

2

Pada tabel 1 diatas menjelaskan tentang hasil rekap kuisioner yang didapatkan dari lembar pretest, dimana yang menjawa pilihan "YA" sebanyak 2 peserta hanya butir kuisioner 1 (K1) dan yang menjawab "TIDAK" sebanyak 11 butir pertanyaan dari K2 hingga K12.

Selanjutnya untuk melihat jumlah persentasi pengetahuan peserta dalam memahami maksud peranyaan dengan lembar pretest dapat dilihat pada tabel 2 berikut.

Tabel 2 Pretest tingkat pengetahuan peserta penggunaan aplikasi SLIMS

\begin{tabular}{clcc}
\hline No & Pertanyaan & Pertanyaan (Ya) & \% Pertanyaan (Ya) \\
\hline 1 & K1 & 2 & $100 \%$ \\
2 & K2 & 0 & $0 \%$ \\
3 & K3 & 0 & $0 \%$ \\
4 & K4 & 0 & $0 \%$ \\
5 & K5 & 0 & $0 \%$ \\
6 & K6 & 0 & $0 \%$ \\
7 & K7 & 0 & $0 \%$ \\
8 & K8 & 0 & $0 \%$ \\
9 & K9 & 0 & $0 \%$ \\
10 & K10 & 0 & $0 \%$ \\
11 & K11 & 0 & $0 \%$ \\
12 & K12 & 0 & $0 \%$ \\
\hline \multicolumn{4}{c}{ Total } \\
\cline { 2 - 3 }
\end{tabular}

Tingkat total pengetahuan

peserta dalam menggunakan aplikasi slims

$8.3 \%$

Sebelum dilatih

Tabel 2 diatas menjelaskan jumlah persentasi pengetahuan peserta pelatihan aplikasi slims dengan rumus, Kuisioner $=$ (Nilai rata rata $/$ jumlah kuisioner $) \times$ nilai persentasi $(100 \%)$. Total persentasi pengetahuan sebelum dilakukan pelatihan tentang aplikasi slims didapatkan $8.3 \%$ dimana hal ini menggambarkan bahwa peserta belum memahami cara menggunakan aplikasi slims

2. Data Posttest

Peserta sebanyak 2 orang, berikut hasil rekap data posttest dengan skala guttment pada tabel 3 berikut ini.

Tabel 3 Rekap lembar posttest

\begin{tabular}{|c|c|c|c|c|c|c|c|c|c|c|c|c|c|}
\hline \multirow{2}{*}{ No } & \multirow{2}{*}{$\begin{array}{l}\text { Peserta } \\
\text { Pelatihan } \\
\text { (P) }\end{array}$} & \multicolumn{12}{|c|}{ KUISIONER (K) } \\
\hline & & $\mathrm{K} 1$ & $\mathrm{~K} 2$ & K3 & K4 & K5 & K6 & K7 & K8 & K9 & $\mathrm{K} 10$ & $\mathrm{~K} 11$ & $\mathrm{~K} 12$ \\
\hline 1 & P1 & 1 & 1 & 1 & 1 & 1 & 1 & 1 & 1 & 1 & 1 & 1 & 1 \\
\hline 2 & $\mathrm{P} 2$ & 1 & 1 & 1 & 1 & 1 & 1 & 1 & 1 & 1 & 1 & 1 & 1 \\
\hline & Total & 2 & 2 & 2 & 2 & 2 & 2 & 2 & 2 & 2 & 2 & 2 & 2 \\
\hline
\end{tabular}




\section{Total Data $\quad 2$}

Pada tabel 3 diatas menjelaskan tentang hasil rekap kuisioner yang didapatkan dari lembar pretest, setelah dilakukannya pelatihan aplikasi slims sebanyak 2 orang dan 12 butir pertanyaan, peserta yang menjawab pilihan "YA" yaitu semua butir pertanyaan dan yang menjawab "TIDAK" tidak ada.

Selanjutnya untuk melihat jumlah persentasi pengetahuan peserta dalam memahami maksud pertanyaan dengan lembar posttest dapat dilihat pada tabel 4 berikut.

Tabel 4 Posttest tingkat pengetahuan peserta

\begin{tabular}{|c|c|c|c|}
\hline No & Pertanyaan & \% Pertanyaan (Ya) & \% Pertanyaan (Ya) \\
\hline 1 & K1 & 2 & 100 \\
\hline 2 & $\mathrm{~K} 2$ & 2 & 100 \\
\hline 3 & K3 & 2 & 100 \\
\hline 4 & $\mathrm{~K} 4$ & 2 & 100 \\
\hline 5 & K5 & 2 & 100 \\
\hline 6 & K6 & 2 & 100 \\
\hline 7 & K7 & 2 & 100 \\
\hline 8 & K8 & 2 & 100 \\
\hline 9 & К9 & 2 & 100 \\
\hline 10 & K10 & 2 & 100 \\
\hline 11 & K11 & 2 & 100 \\
\hline \multirow[t]{3}{*}{12} & $\mathrm{~K} 12$ & 2 & 100 \\
\hline & Total & 24 & 1200.0 \\
\hline & Rata rata & 2.0 & 100.0 \\
\hline \multicolumn{3}{|c|}{$\begin{array}{l}\text { peserta dalam menggunakan aplikasi slims } \\
\text { susudah dilatih }\end{array}$} & $100.0 \%$ \\
\hline
\end{tabular}

Tabel 4 diatas menjelaskan jumlah persentasi pengetahuan peserta pelatihan aplikasi slims dengan rumus, Kuisioner $=$ (Nilai rata rata $/$ jumlah kuisioner $) \mathrm{x}$ nilai persentasi $(100 \%)$. Sehingga didapatkan pilihan "YA" 100\% dikarenakan seluruh peserta sangat memahami maksud seluruh (12) butir pertanyaan tersebut, sedangkan untuk peserta tidak memahami maksud 12 butir pertanyaan dengan persentasi $0 \%$. Total persentasi pengetahuan sesudah dilakukan pelatihan tentang aplikasi slims didapatkan $100 \%$.

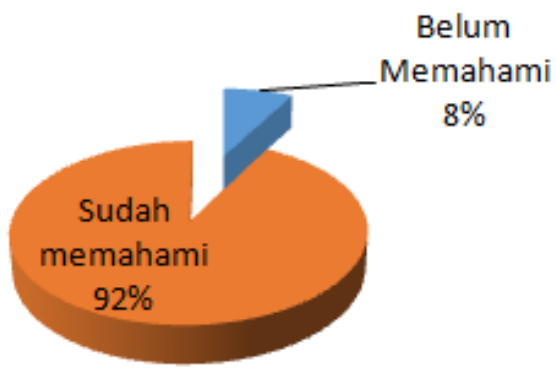

Gambar 3. Grafik pemahaman peserta pelatihan pretest dan posttest 
Untuk mengetahui selisih kenaikan persentasi maka dilakukan dengan skala guttman dengan nilai $8.3 \%$ - $100 \%=91.7 \%$. Sehingga dapat dilihat peningkatan pemahaman peserta dalam menggunakan aplikasi slims dengan tingkat $91.7 \%$, dengan peningkatan tersebut bahwa peningkatan pemahaman peserta dalam menggunakan aplikasi slims sangat baik sehingga pengalaman pelatihan ini dapat diterapkan untuk merapikan dan mengendalikan buku buku didalam perpustakaan.

\section{KESIMPULAN}

Bagian Dari rangkaian kegiatan program pengadian kepada masyarakat dalam pelatihan penerapan sirkulasi perpustakaan menggunakan aplikasi SLIMS, dapat disimpulkan sebagai berikut.

1. Berdasarkan tes uji pemahaman peserta menggunakan lembar pretest sebelum dilakukan pelatihan aplikasi dengan skala guttment didapatkan pengetahuan peserta belum memahami bagaimana bentuk aplikasi perpustakaan dan cara menggunakan aplikasi SLIMS hal ini dapat dilihat dari hasil analisa persentasi dengan jumlah persentasi $8.3 \%$, namun setelah dilakukan pelatihan kepada peserta dengan mengikuti tahap demi tahap kemudian pemahaman peserta menjadi meningkat dengan jumlah persentasi $100 \%$ hingga menjadi ideal namun dengan catatan masih dalam pembinaan.

2. Berdasarkan pemahaman peserta dari sebelum dan sesudah dilakukannya pelatihan kemampunan menggunakan aplikasi perpustakaan dalam hal menggunakan software slims didapatkan selisih peningkatan pengetahuan yang sangat signifikan yaitu sebesar $91.7 \%$, jumlah tersebut sudah masuk kategori ideal bagi pengguna pemula.

\section{DAFTAR PUSTAKA}

Azwar, M. (2013). Membangun Sistem Otomasi Perpustakaan Dengan Senayan Librari Manajemen Sistem ( SLIMS ). Khizanah Al-Hikmah, 1(1), 19-33.

Cahyono, J. E., \& Heryanto. (2013). Analisis pemanfaatan senayan library management system (slims) dikantor perpustakaan dan arsip daerah kota salatiga. Jurnal Ilmu Perpustakaan, 2(3), 10.

Costaner, L., Guntoro, \& Lisnawita. (2018). Pelatihan Keterampilan Membuat Slide Persentasi Efektif Dengan Efek Gradasi Pada Mahasiswa Fakultas Ilmu Budaya Unilak. Jurnal Dinamisi , 2(2), 322-327. https://doi.org/10.31849/dinamisia.v2i2.1469

Dewi, L., \& Suhardini, A. D. (2014). Peran perpustakaan dan tenaga perpustakaan sekolah/madrasah dalam meningkatkan pendidikan disekolah/madrasah. EduLib, 1, 57-77.

Hikmawan, R. A., Astuti, E. S., \& Riyadi. (2015). Desain sistem informasi perpustakaan digital ( Studi Kasus pada SMA Negeri 1 Pasuruan ). Jurnal Administrasi Bisnis, 28(2), 1-10.

Khotimah, Nu. (2017). Penerapan sistem otomasi SLIMS 7 cendana pada pelayanan sisrkulasi diperpustakaan MTs Negri 9 Bantul. YOGYAKARTA.

Rahadian, G., \& Anwar, R. K. (2014). Peranan Perpustakaan Sekolah Dalam Meningkatkan Budaya Gemar Membaca. Jurnal Kajian Informasi Dan Perpustakaan, 2(1), 27-36.

Rahmadhani, D., \& Marlini. (2015). Pemanfaatan software slims di upt perpustakaan kopertis wilayah x. Jurnal Ilmu Informasi Perpustakaan Dan Kearsipan, 4(1), 192-203.

Saputra, A. (2017). Panduan Modifikasi Modul Membership SliMS 7 Cendana Andi. In Komputer (p. 8). Padang: UPT Perpustakaan Universitas Andalas 20.

Susanto, S. E. (2010). Desain dan standar perpustakaan digital. Jurnal Perpustakaan Indonesi, $10(2), 17-23$.

Syamsul Mubaroq. (2013). Profil Sekolah Menengah Islam Terpadu AL Fityah Pekanbaru. 